\title{
FLUJOMETRÍA DOPPLER DE ARTERIAS UTERINAS COMO PREDICTOR DE MACROSOMIA FETAL
}

\author{
Oscar Antonio Limay Ríos¹, Antonio Mambret Luna Figueroa², Dionicio Bernal Cabrera³.
}

\begin{abstract}
RESUMEN
Objetivos: Determinar la relación entre el índice de pulsatilidad promedio de las arterias uterinas tomadas por ecografía en gestantes entre las 11 a 14 y 20 a 26 semanas de gestación con la macrosomía neonatal. Materiales y métodos: Estudio prospectivo, longitudinal, analítico. Se incluyeron a 3,279 gestantes atendidas en el Instituto Nacional Materno Perinatal entre el periodo 2011 a 2014, de los cuales 952 fueron pacientes captadas entre las 11 a 14 semanas y 2327 entre las 20 a 26 semanas, se formó dos grupos: 11 a 14 y 20 a 26 semanas; los pesos considerados para la comparación fueron: 3,600, 3,800, 4,000, 4,200 y 4,400 gramos, se realizó una correlación por el método de Pearson, la significación estadística se realizó por medio de la prueba de Chi cuadrado para ambos grupos, para calcular la probabilidad de ocurrencia de los eventos se calculó el odss ratio y para evaluar la precisión se utilizaron intervalos de confianza, posteriormente se construyó una curva ROC para precisar la sensibilidad y la tasa de falsos positivos. Resultados: Hubo un aumento del porcentaje de los recién nacidos macrosómicos sobre la población general pasando de un $6 \%$ a un $9 \%$ en el periodo 1995 a 2015. Para las 11 a 14 semanas con un punto de corte menor o igual a 1.32 del Índice de Pulsatilidad promedio de las arterias uterinas, se encontró una probabilidad de 1.6 veces de que el recién nacido sea macrosómico, con una significación estadística de 0.056 para la prueba de Chi cuadrado, al realizar la curva ROC esta nos muestra una sensibilidad del $40 \%$ y una tasa de falsos positivos del $20 \%$, de la misma forma para las 20 a 26 semanas para un punto de corte menor o igual a 0.80 del Índice de Pulsatilidad promedio de las arterias uterinas, se encontró una probabilidad de 1.7 veces de que el recién nacido sea macrosómico con una significación estadística de 0.036 para la prueba de Chi-cuadrado, al realizar la curva ROC esta nos muestra una sensibilidad del $26 \%$ y una tasa de falsos positivos del $20 \%$; por lo tanto podemos afirmar que si existe una correlación en ambos con la macrosomía neonatal pero que su sensibilidad es baja y su tasa de falsos positivos es alta, siendo mejor la toma de la ecografía entre las 11 a 14 semanas. Conclusiones: Existe correlación entre el Doppler de las arterias uterinas tomado entre las 11 a 14 semanas y entre las 20 a 26 semanas con la macrosomía neonatal, pero su sensibilidad es baja y su tasa de falsos positivos es alta, siendo mejor la toma de la ecografía entre las 11 a 14 semanas.
\end{abstract}

Palabras Claves: Macrosomía; Índice de Pulsatilidad; Arterias uterinas (Fuente DeCS BIREME).

\section{ABSTRACT}

Objectives: To determine the relationship between the average pulsatility index of the uterine arteries taken by ultrasound in pregnant women between 11 and 14 and 20 to 26 weeks of gestation with neonatal macrosomia. Materials and methods: Prospective, longitudinal, analytical study. A total of 3,279 pregnant women attended at the National Maternal Perinatal Institute between 2011 and 2014, of whom 952 were patients between 11 and 14 weeks and 2327 between 20 and 26 weeks, two groups were formed: 11 to 14 and 20 to 26 weeks; The weights considered for the comparison were: 3,600, 3,800, 4,000, 4,200 and 4,400 grams, a correlation was performed by the Pearson method, statistical significance was performed by means of Chi square test for both groups, to calculate the probability Of occurrence of events was calculated odss ratio and to evaluate the precision were used confidence intervals, subsequently constructed a ROC curve to precise sensitivity and false positive rate. Results: There was an increase in the percentage of macrosomic infants over the general population from $6 \%$ to $9 \%$ in the period 1995 to 2015 . For 11 to 14 weeks with a cutoff point less than or equal to 1.32 of the Index Of mean pulsatility of the uterine arteries, we found a probability of 1.6 times that the newborn is macrosomic, with a statistical significance of 0.056 for the chi square test, when performing the ROC curve this shows a sensitivity of $40 \%$ and A false positive rate of $20 \%$, likewise for 20 to 26 weeks for a cutoff point less than or equal to 0.80 of the Average Pulsatility Index of the uterine arteries, a probability of 1.7 times was found that the newly Being born macrosomic with a statistical significance of 0.036 for the chi-square test, when performing the ROC curve this shows a sensitivity of $26 \%$ and a false-positive rate of $20 \%$; Therefore we can affirm that if there is a correlation in both with neonatal macrosomia but that its sensitivity is low and its rate of false positives is high, being better the ultrasound between 11 to 14 weeks. Conclusion: There is a correlation between Doppler of the uterine arteries taken between 11 to 14 weeks and between 20 to 26 weeks with neonatal macrosomia, but its sensitivity is low and its rate of false positives is high, taking the Ultrasound between 11 and 14 weeks.

Key Words: Macrosomía; Pulsatility Index; Uterine Artery (Source: MeSH NLM).

\section{INTRODUCCIÓN}

Desde hace varias décadas muchos estudios han reportado numerosas complicaciones obstétricas y perinatales debidos a la obesidad materna y la macrosomía fetal ${ }^{1-6}$, es por eso que el presente estudio aporta herramientas para controlar estas patologías, ayudando a prevenir en el futuro problemas de salud como la obesidad, la diabetes y las enfermedades cardiovasculares; El desarrollo de un método que ayude a detectar el riesgo de la macrosomía neonatal es nuestro propósito el cual lo podemos detectar midiendo el Índice de Pulsatilidad promedio de las arterias uterinas, este índice mientras más bajo es, más está relacionado con la macrosomía fetal y debe ser tomado entre las 11 a 14 y entre las 20 a 26 semanas aprovechando la toma de la ecografía genética y morfológica; detectando el riesgo

Médico GínecoObstetra. Magíster en Salud Pública. Jefe de la Unidad de Investigación. Asistente del Servicio de Medicina Fetal del Instituto Nacional Materno Perinatal. Lima Perú.

2 Médico GínecoObstetra. Profesor Principal de la Universidad Nacional Mayor de San Marcos. Director Ejecutivo de Investigación, Docencia y Atención en Obstetricia y Ginecología del Instituto Nacional Materno Perinatal. Lima-Perú.

3 Médico Residente de Radiología de la Universidad Nacional de Cajamarca con rotación externa en Servicio de Medicina Fetal del Instituto Nacional Materno Perinatal. Lima-Perú. 
de padecer macrosomía, nos permitirá realizar medidas correctivas para controlar el peso tanto materno como fetal; como sabemos la macrosomía fetal está acompañada de una tasa de letalidad del $1 \%^{7}$ y su incidencia es muy variable siendo en el Instituto nacional materno perinatal de Lima (INMP) del $7 \%$ y el promedio nacional de $11 \% \%^{7,8}$, los factores predictivos de macrosomía fetal son ganancia ponderal excesiva materna, feto de sexo varón, edad mayor de 30 años, obesidad, antecedente de feto grande, talla mayor de $160 \mathrm{~cm}$, diabetes familiar y la sobre nutrición materna ${ }^{7,9}$, por lo cual inferimos que existe una relación directa entre el aporte sanguíneo de la madre al feto y la ganancia de peso fetal, esta relación ha sido investigada con la disminución del aporte sanguíneo de la madre al feto como es el caso de la pre eclampsia, sin embargo, en el lado opuesto por el excesivo aporte sanguíneo hay pocos estudios al respecto ${ }^{10-15}$.

Estudios observacionales y de cohortes en Inglaterra, Escandinavia, India y Holanda fueron los primeros que mostraron la estrecha asociación entre el bajo peso al nacer y el desarrollo posterior de enfermedades crónicas ${ }^{13,18,20,23-25}$. Se han realizado experimentos en ratas gestantes a los cuales se les suministro dietas altas en carbohidratos y grasas, las ratas bebes presentaron a los seis meses post natal obesidad, hipotensión muscular, hiperfagia, disfunción endotelial e hipertensión ${ }^{26}$, por lo tanto, es razonable pensar que esta asociación se extiende también a humanos nacidos por sobre el percentil 90 de la curva del crecimiento ${ }^{27-33}$

El Doppler materno fetal se ha usado en obstetricia desde $1977^{34}$, cuando se midió por primera vez en Inglaterra el flujo doppler de la arteria umbilical, el Doppler de la arteria uterina lo utilizó por primera vez en $1983^{35}$, posteriormente se observó que un IPAU condicionaba mayor riesgo de pre eclampsia y restricción del crecimiento intrauterino ${ }^{36-38}$, sin embargo, no existen trabajos entre el valor bajo del IPAU con la macrosomía fetal; en el año $2000^{11}$, se encontró que las pacientes en las que las arterias uterinas lograban formas de onda sin incisura proto diastólica antes de las 20 semanas obtenían neonatos con mayor ponderado fetal; en el año $2010^{15}$ se elaboró un estudio con doppler 3D con la finalidad de investigar las correlaciones entre volumen placentario del primer trimestre, índices de vascularización placentaria y los pesos de los recién nacidos; se estudiaron la posible predicción de macrosomía y restricción del crecimiento intrauterino, las correlaciones entre el volumen de la placenta y el grupo de restricción de crecimiento intrauterino de los recién nacidos fueron significativas, la misma correlación también se produce cuando el fenómeno se presenta al revés; en el $2013^{10}$ en el Perú se realizó un estudio transversal observacional en la cual se tomó el IPAU donde se encontró que a menor IP, mayor es el peso del recién nacido, esta correlación fue significativa.

Las evidencias experimentales y epidemiológicas han demostrado que las modificaciones del ambiente intrauterino pueden conllevar a un mayor riesgo de padecer patologías no transmisibles en la vida adulta, lo que se conoce como hipótesis del origen temprano de las enfermedades o programación fetal ${ }^{39}$, por lo tanto, los eventos implicados en el desarrollo fetal normal tienen efectos a largo plazo e influyen en la salud durante la vida adulta ${ }^{40-45}$, con la aparición de enfermedades como: ateroesclerosis, hipertensión arterial, accidente cerebrovascular, diabetes mellitus tipo 2 y dislipidemias, estos cambios intrauterinos ocurren en los genes a través de modificaciones epigenéticas, como la metilación del ADN, la acetilación de las de las histonas y la fosforilación de las mismas, que pueden ser la base del mantenimiento a largo plazo de los efectos de la programación fetal ${ }^{46,47}$, el consumo de nutrientes en exceso influye en periodos críticos durante la gestación que afectan el desarrollo del tejido adiposo y de los centros hipotalámicos que regulan la ingesta calórica y el crecimiento ${ }^{48}$, también, por otro lado en modelos experimentales en ratas, se ha demostrado que la restricción calórica durante la gestación induce el desarrollo de la obesidad, diabetes e hipertensión arterial de las crías ${ }^{49,50}$, este efecto es potenciado por una dieta rica en grasas en la vida post natal ${ }^{51}$, este fenómeno contradictorio no lo es en sí, ya que depende en qué periodo crítico del embarazo acurre la inadecuada nutrición (Tabla 1), es así que la sobre nutrición influye también en la grasa del feto en los mismos periodos críticos descritos para la restricción calórica ${ }^{42}$, modelos en roedores alimentados con dietas ricas en sacarosa han demostrado que las crías desarrollan obesidad, hígado graso y un aumento en los niveles de lipoproteínas de baja densidad paradójicamente estos animales presentaron una mayor sensibilidad a la insulina a nivel muscular con una tolerancia a la glucosa normal ${ }^{52,53}$; estudios en primates y ratones han demostrado que el exceso de consumo de grasas en forma crónica en la madre conduce a largo plazo a obesidad, hipercolesterolemia, resistencia a la insulina e hipertensión ${ }^{54-56}$, entre las causas de estas patologías están la activación de varios marcadores de estrés oxidativo y la activación prematura de genes por la vía del gluconeogénesis pudieran ser la causa de este fenómeno ${ }^{56}$;en los humanos la obesidad materna durante la gestación incrementa el riesgo de obesidad, diabetes tipo2, enfermedad cardiovascular y cáncer en su descendencia ${ }^{57}$, además, interesante notar que los hijos de madres obesas acumulan una mayor cantidad de tejido adiposo y desarrollan resistencia a la insulina desde el nacimiento ${ }^{58}$, otro estudio realizado en 3,074 madres obesas durante la gestación demostró que sus hijos presentaban obesidad e hipertensión arterial desde la niñez ${ }^{59,72}$, estas alteraciones observadas en la primera generación de hijos nacidos de madres obesas, también puede tener repercusiones en las siguientes generaciones dado que estudios animales han mostrado una mayor propensión a obesidad y síndrome metabólico en la segunda generación de animales expuestos a obesidad materna ${ }^{60}$; la hiperglicemia en la diabetes gestacional principalmente en el tercer trimestre del embarazo, conduce a hiperglicemia e hiperinsulinemia fetal lo que propicia un mayor crecimiento debido a acumulación de tejido adiposo ${ }^{61,62}$, la diabetes gestacional a largo plazo también afecta al hijo, en un estudio realizado entre jóvenes de 18 a 27 años, mostraron que tenían 2 a 4 veces mayor riesgo de desarrollar obesidad y síndrome metabólico que 
mujeres nacidas de embarazos normales ${ }^{63}$, los factores exógenos son más importantes en etapas posteriores de la gestación tanto para el peso como para la talla fetal y este equilibrio entre influencias genéticas y exógenas (nutrición materna, factores placentarios) es controlado por las hormonas fetales ${ }^{66}$.

La posibilidad de crecimiento del feto en desarrollo en condiciones normales es determinada por factores genéticos propios del feto y por el ambiente uterino materno, este último depende del funcionamiento correcto de la línea de suministro placentario; la interferencia con esta línea, ya sea por aumento de la transferencia (glucosa) o anomalías vasculares (menor transferencia) causa inhibición o aceleración del crecimiento fetal, el peso del recién nacido está íntimamente ligado a la ganancia de peso durante el embarazo, por esta razón, la evaluación nutricional de la embarazada constituye una acción fundamental dentro del paquete básico de prestaciones que deben brindarse durante el período prenatal ${ }^{64}$; tradicionalmente se detecta al riesgo de dar a luz a bebes con peso igual o mayor de $4 \mathrm{~kg}$, con la utilización de diversos normogramas que clasifica a las madres según su estado nutricional y así orientarlas para que lleven una nutrición adecuada durante el embarazo ${ }^{14,63-66}$, sin embargo, estas tablas son muy dispares entre si y deben de adecuarse a la realidad de la población gestante de un país o región; estos concluyen que el indicador más sensible de composición corporal y de obesidad materna es el IMC por lo cual el riesgo de macrosomía se va incrementado conforme aumenta del IMC de la madre, así, las mujeres obesas con IMC $>30$ tienen en promedio 3 veces más riesgo de tener hijos macrosómicos, de igual manera la proporción de macrosómicos en mujeres obesas va desde 8 al 17\% 2,5,68,69, la macrosomía es más frecuente en madres obesas que el resto de la población, independientemente que sean diabéticas o no, estos hallazgos son significativos ${ }^{1}$, por lo tanto mujeres con mayor IMC tienen mayor resistencia a la insulina por lo cual hay un aumento de la glucosa materna que condiciona una mayor secreción de insulina en el feto esto produce un recién nacido más grande, esta fisiopatología es más difícil de explicar en aquellos macrosómicos cuyas madres también son obesas que presentan un test de tolerancia a la glucosa normal, es decir el desarrollo de la macrosomía también se observa en mujeres obesas con glucosa normal, estos sugiere que existen otros mecanismos que promueven el excesivo crecimiento fetal ${ }^{1}$, como son el aumento de los triglicéridos ya que en las madres obesas se produce un aumento de transmisión de triglicéridos y ácidos grasos al feto gracias a la lipasa placentaria y a un incremento en el flujo de aminoácidos que puede estimular la hiperinsulinemia fetal incrementando la disponibilidad de glucosa para el transporte feto materno ${ }^{5}$; el excesivo incremento de peso materno aumenta el riesgo de macrosomía, donde el riesgo aumenta cuatro veces en gestantes que ganaban más de $15 \mathrm{~kg}$ durante el embarazo ${ }^{4}$. Estudios previos han demostrado que la ganancia de peso gestacional dentro de los rangos recomendados por el Instituto de Medicina de los Estados Unidos es asociado con menor número de bebes macrosómicos ${ }^{70,71}$; está demostrado también que la ganancia de peso durante la segunda mitad del embarazo influye más en la macrosomía fetal que el peso previo de la madre antes del embarazo ${ }^{9}$, además se encontró que el consumo de proteínas y grasa de origen animal tiene una asociación con la ganancia de peso materno y el peso al nacer, mientras el consumo de carbohidratos está asociado inversamente al peso fetal ${ }^{73}$; la temporal tendencia en el incremento de peso al nacer y macrosomía no es enteramente debido al incremento en el IMC materno y obesidad materna, aunque parece ser la principal ${ }^{1}$, pero, también puede estar determinado por el peso al nacer de la madre que podría predecir el peso del recién nacido ${ }^{68}$, por otro lado, la mayor ganancia de peso previo al embarazo condiciona un mayor riesgo de bebes grandes para la edad gestacional21,74,75; la ganancia de peso durante el embarazo varía de acuerdo al país estudiado y al índice de masa corporal que tiene la paciente en promedio varía de 8 a $11 \mathrm{~kg}^{76-78}$; además, también existe una asociación con el recién nacido macrosómico que se incrementa con la edad materna ${ }^{4,68,70}$, ya que como sabemos, el incremento de IMC también está asociado con incremento de la edad materna ${ }^{3}$, es también necesario mencionar que a mayor talla materna mayor peso fetal, esta asociación es menos fuerte en el caso del padre ${ }^{79,80}$ y hay estudios que por el contrario, la talla del padre no parece contribuir mucho al tamaño del recién nacido, por otra parte en cuanto al sexo del recién nacido es el masculino el que está más asociado a macrosomía ${ }^{81,9,80}$, otros autores no encuentran diferencias significativas ${ }^{1,3}$.

En cuanto a las complicaciones fetales, el recién nacido macrosómico presenta una serie de riesgos a corto plazo como el aumento de frecuencia de complicaciones obstétricas como distocia de hombros, laceración perineal, nacimiento por cesárea, riesgo de parálisis braquial, asfixia, hemorragia cerebral del recién nacido, mayor riesgo de hipoglicemia y defectos al nacimiento ${ }^{3}$, además una ganancia excesiva de peso y un mayor IMC en la madre aumenta la tasa de cesárea en forma significativa2-5,9,74,77,82, además existe un el incremento de depósito de grasas en tejidos blandos de la pelvis, mayor aumento de riesgo de hemorragia posparto por haber una mayor área de implantación de la placenta,69; el factor genético o de una "herencia cultural" por transmisión de modelos y patrones de alimentación poco saludables, son los causantes de la obesidad materna, es difícil de diferenciarlos entre sí, lo más probable es que sea una mezcla de factores, donde las conductas alimentarias familiares parecen ser las más relevantes relevantes ${ }^{83}$.

\section{MATERIALES Y MÉTODOS}

Tipo de Investigación: según la tendencia o enfoque: Investigación cuantitativa, según la orientación - finalidad: Investigación clínica. Diseño de la investigación: Observacional, prospectivo, longitudinal, 
Analítico. Nivel de la investigación: Correlacional. Tipo de Estudio: Prospectivo, Longitudinal, Analítico. Diseño: Se realizó un estudio analítico, prospectivo en la cual se tomó la ecografía obstétrica Doppler de las arterias uterinas entre las 11 a 14 semanas, se midió la biometría fetal y se evaluó su morfología, cuando se verifico su bienestar fetal adecuado se le tomó el doppler de las arterias uterinas, específicamente su Índice de Pulsatilidad promedio, posteriormente se hizo el mismo procedimiento entre las 20 a 26 semanas, se esperó que nacieran los bebes se procedió a verificar y clasificar su peso en cinco grupos al nacer los cuales son: mayor o igual de 3,600 gramos, mayor o igual de 3,800 gramos, mayor o igual al 4,000 gramos, mayor o igual a 4,200 gramos y el último grupo mayor o igual de 4,400 gramos; se procedió a recolectar datos de la gestante así como del neonato, posteriormente se correlacionó el Doppler promedio de las uterinas con el peso neonatal mediante la prueba de Pearson luego se estableció la significancia estadística con la prueba de chi2, para la determinación de las pruebas de hipótesis se procedió a realizar un odds ratio con su respectivo intervalo de confianza, correlación de dos variables dependientes, así como la curva ROC para encontrar el punto de corte ideal, luego se procedió a calcular la sensibilidad, la especificidad y la tasa de falsos positivos para establecer la validez de la prueba. Población: Gestantes atendidas en el Instituto Nacional Materno Perinatal y controladas, con parto, puerperio y recién nacido atendidos en la institución que cumplan los siguientes criterios de selección. Criterios de inclusión: Gestantes con controles prenatales en nuestra institución, feto único, Parto de feto vivo, Feto sin malformaciones, que se hayan tomado la ecografía entre las 11 a 14 semanas y/o entre las 20 a 26 semanas del embarazo. Criterios de Exclusión para las expuestas: Más de 14 semanas al momento de la captación, gestante que no recuerden su fecha de última menstruación. Tiempo: Desde enero del 2011 hasta diciembre del 2014. Unidad de Análisis: Gestante atendida en el Instituto Nacional Materno Perinatal. Unidad de Muestreo: Historia Clínica Perinatal. Tamaño de la muestra: Todas las gestantes que acudieron al servicio de medicina fetal. Tipo de muestreo: No probabilística por conveniencia. Variable dependiente (consecuencia): Macrosomía neonatal. Variable independiente (causa): Índice de Pulsatilidad promedio de las arterias uterinas. Variable interviniente (participa con la independiente): Edad gestacional 11 a 14 semanas y 20 a 26 semanas. Método: Método Causal Comparativo. Técnica: Observación documental. Instrumento de recolección de datos: Formulario para llenar datos maternos y neonatales. Plan de Tabulación y análisis: Se utilizó la prueba de correlación para muestras independientes, posteriormente se procede a sacar las curvas ROC para encontrar los puntos de corte y el área bajo la curva, para darle más fuerza al estudio se procedió paralelamente a sacar el OR y sus intervalos de confianza, posteriormente se comparó la curva ROC con el OR encontrándose convergencia en los puntos de corte. Plan de Análisis: el estudio se realizó en el servicio de medicina fetal en pacientes que tengan su control Doppler entre las semanas 11 y 14 o entre las 20 y 26 semanas. Según reportes institucionales y en base a estudios previos, la población estará conformada por 3,883 gestantes para el periodo de estudio planteado, luego se excluyó a 650 pacientes debido a que presentaban en su informe ecográfico alguna patología fetal, placentaria, del líquido amniótico del doppler o cuyos bebes no nacieran en la institución quedando un total de 3,233 gestantes, de los cuales a 929 se les tomo la ecografía Doppler entre las 11 a 14 semanas y 2304 entre las 20 a 26 semanas. Los pesos de los recién nacidos fueron tomados de las historias clínicas neonatales y se definieron como macrosomía a los recién nacidos con un peso mayor o igual a 4000 gramos; el doppler promedio de las arterias uterinas se obtuvo de los informes de ecografía realizados en la Unidad de Medicina Fetal; los datos fueron verificados mediante la revisión de múltiples registros de la Institución; se procedió a la confección de una base de datos, conformada por una matriz estructurada en el programa Excel y se exporto la base de datos al programa SPSS versión 22 para su análisis, posteriormente se correlacionó los Doppler hallados con el peso del neonato al nacer que fueron clasificados por conveniencia en 3,600,3,800,4,000,4,200 y 4400 gramos, se estableció una correlación entre el Índice de Pulsatilidad promedio de las arterias uterinas y el peso fetal considerado para comparación en cada uno de estos grupos, encontrándose una correlación adecuada e inversamente proporcional, a mayor peso menor Índice de Pulsatilidad. Etapa de Captación: Las pacientes fueron captadas durante el primer trimestre de embarazo cuando acudan al servicio de ecografía del Instituto Especializado Materno Perinatal entre enero del 2011 a diciembre del 2014. Se cumplió con los criterios de inclusión y exclusión. Técnica de medición de la madre: Las pacientes una vez captadas se centralizaron en un consultorio asignado por el INMP para su seguimiento durante todo el periodo de la gestación, la técnica para evaluar las arterias uterinas es mediante ultrasonografía doppler por vía trans abdominal, esta exploración se realiza en dos etapas de la gestación, la primera entre las 11 a las 14 semanas y entre las 20 a 26 semanas, el transductor se ubica en el borde del útero, en la fosa ilíaca, a la altura de la unión del cuello uterino con el cuerpo uterino, a nivel de la espina isquiática se realiza un barrido de afuera hacia adentro, por el cual se observa la arteria uterina en trayecto ascendente y oblicuo cuando se cruza con los vasos ilíacos de mayor calibre ${ }^{84}$, en ocasiones se puede reconocer muy claramente el característico trayecto tortuoso de la arteria uterina; el doppler de la arteria uterina se utiliza para establecer el riesgo de padecer algunas enfermedades como la restricción del crecimiento intrauterino, la pre eclampsia ${ }^{39,84}$ y el sobre peso fetal ${ }^{10}$, no evalúa la salud fetal ni determina el establecimiento de conductas obstétricas ${ }^{39}$; el doppler de las uterinas se mide en función al índice de pulsatilidad, en condiciones normales el comportamiento de este índice es alto al inicio del embarazo y progresivamente baja la resistencia conforme avanza la edad gestacional, además se utiliza el promedio del IP de las dos uterinas, esto ya está estandarizado según diversos 
autores $^{21,21}$. Las medidas fueron anotadas en el instrumento de recolección de datos. Técnica de medición del recién nacido: Se usó una balanza calibrada diariamente para la medición del peso neonatal. Procesamiento de Datos: Programa Estadístico utilizado para efectuar el análisis y procesamiento de los datos: SPSS, Excel; se realizó los siguientes pasos: clasificación los datos por medio de categorías, revisión crítica de los datos recolectados, establecimiento de un orden o jerarquía entre ellas, análisis y señalamiento de la existencia o inexistencia de relaciones entre los datos, detalle el método analítico a utilizar acorde con el diseño de estudio inicial y presentación de tabla de resultados esperados.

\section{RESULTADOS}

Tabla 1. Correlación entre el doppler de las uterinas y el peso fetal

\begin{tabular}{|c|c|c|c|c|c|c|}
\hline semanas & $\begin{array}{c}\text { Índice de } \\
\text { Pulsatilidad }\end{array}$ & $\begin{array}{c}>=3600 \\
\mathrm{gr}\end{array}$ & $\begin{array}{c}>=3,800 \\
\text { gr }\end{array}$ & $\begin{array}{c}>=4,000 \\
\mathrm{gr}\end{array}$ & $\begin{array}{l}=4,200 \\
\mathrm{gr}\end{array}$ & $\begin{array}{c}0>=4,400 \\
\text { gr }\end{array}$ \\
\hline \multirow{5}{*}{11 a 14} & $<=1.16$ & $\begin{array}{c}1.1 \\
(0.8-1.4)\end{array}$ & $\begin{array}{c}1.4 \\
(0.9-2.0)\end{array}$ & $\begin{array}{c}1.9 \\
(1.2-3.1)\end{array}$ & $\begin{array}{c}2.6 \\
(1.3-5.3)\end{array}$ & $\begin{array}{c}2.9 \\
(1.1-7.7)\end{array}$ \\
\hline & $<=1.25$ & $\begin{array}{c}1.2 \\
(0.9-1.7)\end{array}$ & $\begin{array}{c}1.5 \\
(1.0-2.1)\end{array}$ & $\begin{array}{l}2.0 \\
(1.2-3.2)\end{array}$ & $\begin{array}{c}2.5 \\
(2.0-5.0)\end{array}$ & $\begin{array}{c}3.5 \\
(1.3-9.2)\end{array}$ \\
\hline & $<=1.32$ & $\begin{array}{c}1.3 \\
(1.0-1.7)\end{array}$ & $\begin{array}{c}1.4 \\
(1.0-2.0)\end{array}$ & $\begin{array}{c}1.6 \\
(1.1-2.6)\end{array}$ & $\begin{array}{c}2.0 \\
(1.0-3.9)\end{array}$ & $\begin{array}{c}2.8 \\
(1.1-7.3)\end{array}$ \\
\hline & $<=1.39$ & $\begin{array}{c}1.5 \\
(1.1-2.0)\end{array}$ & $\begin{array}{c}1.5 \\
(1.1-2.2)\end{array}$ & $\begin{array}{c}1.6 \\
(1.0-2.6)\end{array}$ & $\begin{array}{c}2.0 \\
(1.0-3.9)\end{array}$ & $\begin{array}{c}2.8 \\
(1.0-7.4)\end{array}$ \\
\hline & $<=1.5$ & $\begin{array}{c}1.4 \\
(1.1-1.9)\end{array}$ & $\begin{array}{c}1.5 \\
(1.1-2.1)\end{array}$ & $\begin{array}{c}1.7 \\
(1.0-2.6)\end{array}$ & $\begin{array}{c}1.8 \\
(0.9-3.5)\end{array}$ & $\begin{array}{c}3.3 \\
(1.2-9.6)\end{array}$ \\
\hline \multirow{5}{*}{20 a 26} & $<=0.71$ & $\begin{array}{c}1.6 \\
(1.3-1.9)\end{array}$ & $\begin{array}{c}1.7 \\
(1.3-2.1)\end{array}$ & $\begin{array}{c}1.7 \\
(1.2-2.3)\end{array}$ & $\begin{array}{c}1.5 \\
(0.9-2.4)\end{array}$ & $\begin{array}{c}1.4 \\
(0.7-2.8)\end{array}$ \\
\hline & $<=0.75$ & $\begin{array}{c}1.6 \\
(1.3-1.9)\end{array}$ & $\begin{array}{c}1.7 \\
(1.3-2.1)\end{array}$ & $\begin{array}{c}1.6 \\
(1.2-2.2)\end{array}$ & $\begin{array}{c}1.5 \\
(0.9-2.3)\end{array}$ & $\begin{array}{c}1.8 \\
(0.9-3.4)\end{array}$ \\
\hline & $<=0.77$ & $\begin{array}{c}1.5 \\
(1.3-1.8)\end{array}$ & $\begin{array}{c}1.7 \\
(1.3-2.1)\end{array}$ & $\begin{array}{c}1.6 \\
(1.2-2.1)\end{array}$ & $\begin{array}{c}1.4 \\
(0.9-2.2)\end{array}$ & $\begin{array}{c}1.7 \\
(0.9-3.2)\end{array}$ \\
\hline & $<=0.80$ & $\begin{array}{c}1.4 \\
(1.2-1.7)\end{array}$ & $\begin{array}{c}1.6 \\
(1.3-1.9)\end{array}$ & $\begin{array}{c}1.4 \\
(1.1-1.8)\end{array}$ & $\begin{array}{c}1.3 \\
(0.8-2.0)\end{array}$ & $\begin{array}{c}1.5 \\
(0.8-2.8)\end{array}$ \\
\hline & $<=0.83$ & $\begin{array}{c}1.4 \\
(1.2-1.7)\end{array}$ & $\begin{array}{c}1.5 \\
(1.2-1.9) \\
\end{array}$ & $\begin{array}{c}1.3 \\
(1.0-1.8) \\
\end{array}$ & $\begin{array}{c}1.5 \\
(1.0-2.3) \\
\end{array}$ & $\begin{array}{c}1.6 \\
-(0.8-3.0 \\
\end{array}$ \\
\hline
\end{tabular}

Tabla 2. Categorización de las probabilidades de ocurrencia de la macrosomía neonatal

\begin{tabular}{cll}
\hline Categoria & $\begin{array}{c}\text { Probabilidad de que } \\
\text { ocurra el evento }\end{array}$ & \multicolumn{1}{c}{ OR } \\
\hline $\mathbf{0}$ & No & $<1$ \\
I & Si débil & $>=1 \mathrm{y}<1.5$ \\
& Si moderado & $>=1.5 \mathrm{y}>2$ \\
III & Si fuerte & $>=2.0 \mathrm{y}>2.4$ \\
& Si muy fuerte & $>=2.5$ \\
\hline
\end{tabular}

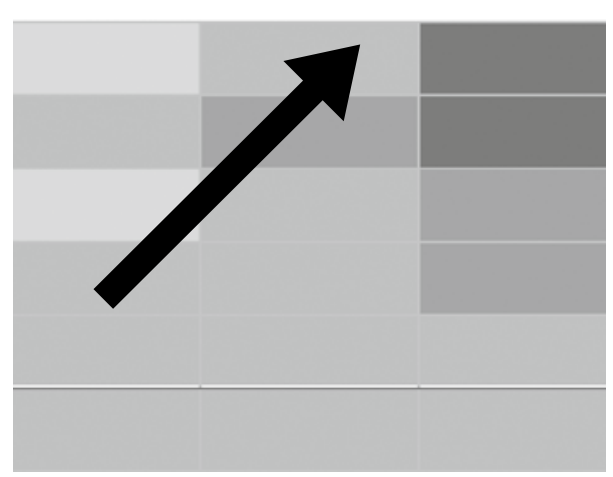

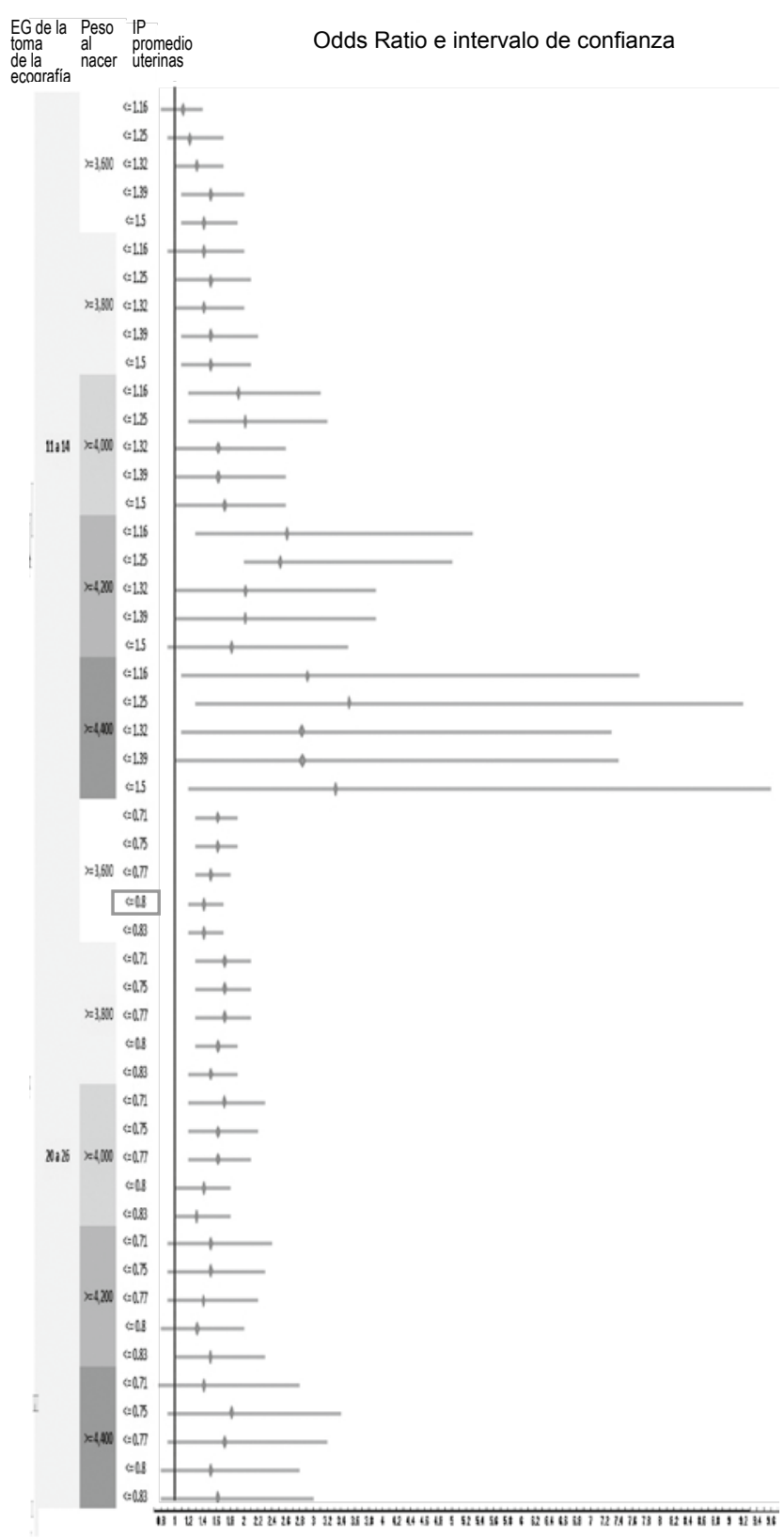

Gráfico 1. OR con sus intervalos de confianza, en correlación con el doppler de las uterinas y el peso fetal

Tabla 3. Coordenadas de la curva ROC para peso mayor o igual a 4,000 gramos

\begin{tabular}{|c|c|c|c|c|c|c|c|}
\hline Semanas & Área & $\begin{array}{c}\text { Positivo } \\
\text { si }<=\end{array}$ & Sensibilidad & $\begin{array}{l}\text { Falsos } \\
\text { positivos }\end{array}$ & OR & IC & Categoria \\
\hline \multirow{5}{*}{11 a 14} & \multirow{5}{*}{0.58} & 1.16 & 0.3 & 0.2 & 2.1 & $1.3-3.3$ & III \\
\hline & & 1.25 & 0.3 & 0.2 & 2.0 & $1.3-3.2$ & II \\
\hline & & 1.32 & 0.4 & 0.2 & 1.7 & $1.1-2.7$ & II \\
\hline & & 1.39 & 0.4 & 0.3 & 1.8 & $1.2-2.8$ & II \\
\hline & & 1.50 & 0.5 & 0.4 & 1.9 & $1.2-2.9$ & ॥ \\
\hline \multirow{5}{*}{20 a 26} & \multirow{5}{*}{0.57} & 0.71 & 0.26 & 0.18 & 1.6 & $1.2-2.2$ & II \\
\hline & & 0.75 & 0.26 & 0.20 & 1.5 & $1.1-2.0$ & II \\
\hline & & 0.77 & 0.26 & 0.20 & 1.5 & $1.1-2.0$ & II \\
\hline & & 0.80 & 0.26 & 0.20 & 1.3 & $1.1-1.7$ & I \\
\hline & & 0.83 & 0.30 & 0.33 & 1.3 & $1.0-1.8$ & I \\
\hline
\end{tabular}




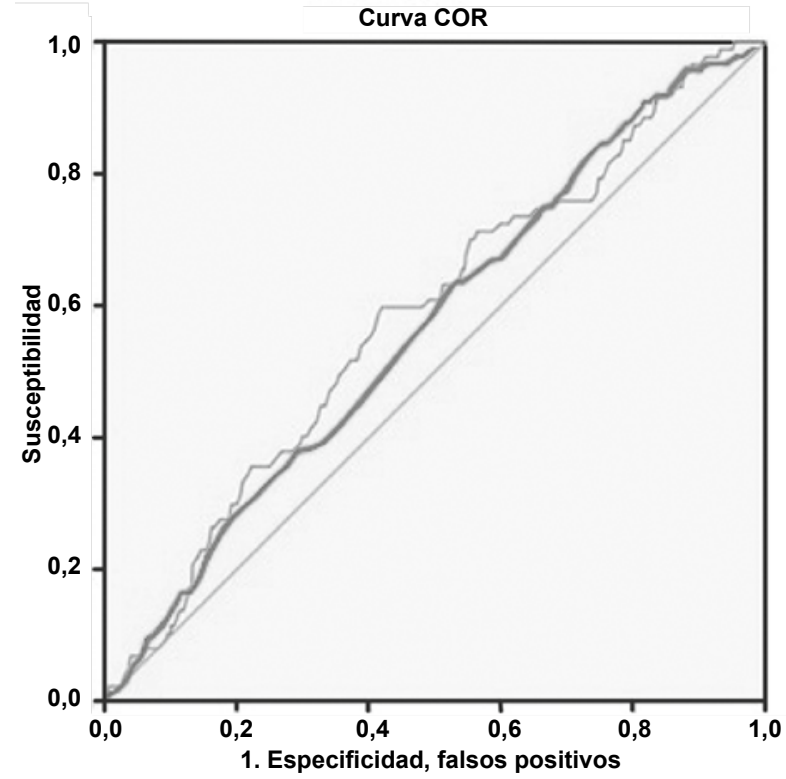

Gráfico 2. Comportamiento de la curva 11 a 14 semanas(azul), 20 a 26 semanas(rojo)

\section{DISCUSIÓN}

Los recién nacidos macrosómicos absolutos equivalen al $9 \%$ del total de la población estudiada, en comparación con los nacidos hace 20 años la población de macrosómicos ha aumentado de un $6 \%$ a un $9 \%$ en la actualidad (anexo 1), este cambio epidemiológico va en correlación con diversos estudios a nivel mundial ${ }^{7,8,22}$, si lo comparamos por los cuatro lustros, vemos que ha ido aumentando progresivamente de $6.4 \%, 7.3 \%, 7.5 \%$ hasta un $8,6 \%$ en el último lustro, si lo comparamos por las dos décadas ha pasado de $6.9 \%$ a $8.1 \%$, es decir, se aprecia claramente que la frecuencia de niños macrosómicos ha aumentado sustancialmente ${ }^{17}$, este fenómeno también ocurre en otros países como los Estados Unidos ${ }^{16}$; la mortalidad perinatal relacionada con un feto grande es decir por encima del percentil 90 es mayor que la de los de tamaño normal ${ }^{7}$, en este grupo están los de origen genético que puede llegar al $70 \%$ y los que pueden considerarse anormalmente grandes que abarca el $30 \%$ de los lactantes, es decir, un neonato que se encuentra por arriba del percentil 90 o más de más de 4,000 gramos al nacer puede ser normal (genético) ${ }^{83}$, en tanto que en embarazos complicados por diabetes $u$ obesidad materna pueden desarrollar un recién nacido anormalmente grande y tener malas consecuencias, como traumatismos en el parto, así como de complicaciones metabólicas y respiratorias del recién nacido ${ }^{3}$, es por eso que hemos intentado idear un método que nos ayude a predecir la macrosomía antes de que se produzca, de tal manera que se haga una intervención en aquellas pacientes donde exista ese riesgo y se minimice o controle la ganancia de peso con un programa de nutrición adecuado, este programa escapa a nuestro estudio y estará dentro de nuestras recomendaciones; hemos apreciado además que el peso promedio en los recién nacidos macrosómicos fue de 4,233 gr y el de los no macrosómicos fue de 3,339 gr, donde podemos manifestar que existe 2.1 veces más probabilidad que el feto con más de $4 \mathrm{Kg}$ nazca por cesárea que por parto vaginal, además de que existe 1.3 veces más probabilidad de que un feto con más de $4 \mathrm{Kg}$ sea masculino que femenino, en cuanto a la talla apreciamos también diferencias ya que en los recién nacidos macrosómicos fue de $52.5 \mathrm{~cm}$ y de los no macrosómicos de $50.1 \mathrm{~cm}$, así mismo el perímetro cefálico en los recién nacidos macrosómicos fue de $35.5 \mathrm{~cm}$ y en los no macrosómicos de $34.3 \mathrm{~cm}$, hemos apreciado también que el porcentaje de bebes macrosómicos por edad gestacional vale decir $37,38,39$ y 40 semanas, es muy superior al porcentaje de bebes macrosómicos por valor absoluto (mayor o igual de $4 \mathrm{Kg}$ ), mientras que en el primero hay un porcentaje de bebes macrosómicos de un 14,9\% (anexo 5) en promedio, en la segunda clasificación clásica está alrededor del $9 \%$ (anexo 1), en este sentido hay una diferencia notoria que nos plantea dos posibilidades: o estamos sobrevalorando el número de recién nacidos macrosómicos cuando lo calculamos por edad gestacional o el cálculo de recién nacido macrosómico en forma absoluta está infravalorando los casos, en cuanto a la sobrevaloración por cálculo de macrosomía de acuerdo a la edad gestacional utilizamos las tablas de Ticona ${ }^{87}$, donde para las 37 semanas el percentil 95 por encima del cual se considera macrosómico es de 3,480 gr, para 38 semanas es de 3,655 gramos, para 39 semanas es de 3,810 gr y para 40 semanas es de 3,930 gramos (anexo 5), además es necesario mencionar que no se ha separado por sexo del recién nacido, tampoco se ha tomado en cuenta si son macrosómicos patológicos o macrosómicos genéticamente predispuestos, talvez esta última separación en dos grupos sea la principal variable a controlar.

Cuando asociamos la toma del doppler de las uterinas entre las 11 a 14 semanas y entre las 20 a 26 semanas con el peso al nacer, apreciamos una correlación positiva con el método de Pearson siendo significativo en ambos grupos (anexo 6), esta conclusión es lógica ya que a mayor vasodilatación menor índice de pulsatilidad del doppler de las arterias uterinas, mayor pasaje de la sangre a la placenta y por lo tanto mayor ingreso de nutrientes al feto que condiciona un bebe macrosómico ${ }^{85,86}$, esta relación es más fuerte cuando se toma entre las 11 a 14 semanas que entre las 20 a 26 semanas, nosotros pensábamos que era al revés ya que se suponía que la relación era más fuerte en este último grupo, pues nuestro trabajo menciona todo lo contrario, esto nos obliga a pensar que existe un factor interviniente mucho más fuerte que enmascara la relación entre las 20 a las 26 semanas, haciendo que a esta edad los valores no sean tan confiables y nos obligan a buscar otros predictores de macrosomía, ese factor interviniente aún no está presente entre las 11 a 14 semanas. Por lo tanto, podemos inferir que a menor edad gestacional de toma del Índice de Pulsatilidad promedio de las arterias uterinas es más fuerte la probabilidad de que pueda predecir mayor peso fetal ${ }^{10-12}$. 
En la tabla 1, el grupo entre las 11 a 14 semanas encontramos los siguientes: cuando el Índice de Pulsatilidad promedio de las arterias uterinas es menor o igual a 1.32 predice pesos fetales mayores o iguales a 4,000 gr, con una probabilidad de 1.6 y con una precisión que fluctúa entre tomado entre 1.1 y 2.6 , y esta probabilidad y precisión aumenta conforme él bebe tiene más peso al nacer como apreciamos en el cuadro 1 con una significación estadística de 0.056 para la prueba de chi cuadrado; Para las 20 a 26 semanas con un punto de corte menor o igual a 0.80 del Índice de Pulsatilidad promedio de las arterias uterinas, se encontró una probabilidad de 1.4 veces de que el recién nacido sea macrosómico con una precisión que fluctúa entre 1.1 a 1.8 , con una significación estadística de 0.036 para la prueba de Chicuadrado; estos hechos nos confirman que la asociación con mayor peso neonatal es más fuerte cuando el doppler es tomado a menor edad gestacional ${ }^{10-12}$

La tabla 2, es un complemento de la tabla 1, donde hemos visto por conveniente clasificar la fuerza de la asociación en relación a una escala de grises de tal manera que varía desde ninguna probabilidad en blanco hasta una extremadamente muy fuerte probabilidad de color mucho más oscuro, con esta clasificación coloreamos los OR y nos arroja un espectro de grises; en correlación con lo descrito en la tabla 1, en el cual evaluamos que el Índice de pulsatilidad promedio de las arterias uterinas más adecuado para predecir macrosomía es cuando es menor o igual a 1.32 para las 11 a 14 semanas; en ese mismo sentido para las 20 a 26 semanas el valor del Índice de pulsatilidad promedio de las uterinas más adecuado es cuando es menor o igual a 0.80 ; se aprecia con más claridad que las celdas más oscuras se orientan hacia la izquierda y hacia arriba del cuadro, conforme se aprecia en la flecha, es decir mejor predicción de mayor peso neonatal a menor edad gestacional de tomado el Índice de Pulsatilidad promedio de las arterias uterinas.

En el gráfico 1 apreciamos que para las 11 a 14 semanas: existe correlación a menor Índice de Pulsatilidad promedio de las arterias uterinas mayor peso neonatal y a menor edad gestacional de la toma del Índice de Pulsatilidad promedio de las arterias uterinas mayor peso del recién nacido, en todos los grupos de casos y control hubo asociación sin embargo hemos escogido el punto de corte menor o igual a 1.32 puesto que es el que más se correlaciona con las coordenadas de la curva ROC, que explicamos líneas abajo, es por eso que cuando se toma la ecografía doppler de las arterias uterinas entre las 11 a 14 semanas y haciendo un punto de corte menor o igual a 1.32, se encontró una probabilidad de 1.6 veces de que el recién nacido tenga un peso mayor o igual a $4 \mathrm{Kg}$ ( macrosómico absoluto), con una significación estadística de 0.056 para la prueba de Chi-cuadrado y para las 20 a 26 semanas con un punto de corte menor o igual a 0.80 , se encontró una probabilidad de 1.4 veces de que el recién nacido tenga un peso mayor o igual a $4 \mathrm{Kg}$ con una significación estadística de 0.036 para la prueba de Chi-cuadrado. Para las 20 a 26 semanas, esta correlación pierde fuerza a medida que aumenta el peso fetal y podemos afirmar que no existe correlación con pesos mayores de 4,200 gramos conforme se puede apreciar en el gráfico, a pesar de que hay muchas más muestra con respecto a las 11 a 14 semanas y es mucho más fácil tomar el doppler de las uterinas a esta edad gestacional, esto nos quiere decir que existen otros factores que influyen en el peso fetal o que el doppler tomado a esa edad carecería de correlación para mayor peso fetal especialmente en fetos de más de 4,200 gramos, sin embargo hemos escogido el punto de corte menor o igual a 0.80 ya que es el mejor que se correlaciona con la curva ROC, por lo tanto podemos afirmar que a menor edad gestacional de toma del Índice de Pulsatilidad promedio de las arterias uterinas es más fuerte la probabilidad de que pueda predecir mayor peso fetal, cuando el doppler es tomado a edades menores hay más uniformidad en los resultados, cuando lo tomamos entre las 20 a 26 semanas es más variable los resultados; por lo tanto para las 11 a 14 semanas, cuando el Índice de Pulsatilidad promedio de las arterias uterinas es menor a 1.32 es más fuerte la probabilidad de un recién nacido de más peso; entre las 20 a 26 semanas: no es clara esta relación. Podemos afirmar también que tomar la ecografía doppler entre las 11 a 14 semanas es mejor que tomarla entre las 20 a 26 semanas ya que en este último grupo el doppler influye menos en el peso neonatal.

En la tabla 3 apreciamos las coordenadas de la curva ROC, en la que el Índice de pulsatilidad promedio de las arterias uterinas más adecuado para predecir macrosomía es cuando es menor o igual a 1.32 para las 11 a 14 semanas, donde las coordenadas de la curva ROC nos muestra una sensibilidad de sólo un $40 \%$ y una tasa de falsos positivos del $20 \%$; en ese mismo sentido para las 20 a 26 semanas el valor del Índice de Pulsatilidad promedio de las arterias uterinas más adecuado es cuando es menor a 0.80 , con una sensibilidad del $26 \%$ y una tasa de falsos positivos del $20 \%$, hemos correlacionado además con las categorías mostradas en el cuadro 2, es decir estamos haciendo una comparación entre la curva ROC con el OR y sus respectivos intervalos de confianza, donde confirmamos que el mejor punto de corte a escoger del Índice de Pulsatilidad promedio de las arterias uterinas es de menor a igual de 1,32 para las 11 a 14 semanas y menor o igual a 0.80 para las 20 a 26 semanas, obsérvese que para este último grupo ha quedado enmarcado dentro de la categoría I (probabilidad débil), mientras que para las 11 a 14 semanas en la categoría II (probabilidad moderada) conforme la clasificación de la tabla 2.

En el gráfico 2 apreciamos que al mostrar la curva ROC en gráfico tanto entre las 11 a 14 semanas en color azul y entre las 20 a 26 semanas en color rojo, podemos afirmar que si existe una correlación en ambos con macrosomía fetal pero que su sensibilidad es baja y su tasa de falsos positivos es alta.

Es extremadamente raro que haya un bebe macrosómico (>= $4 \mathrm{Kg}$ ) con talla menor de $50 \mathrm{~cm}$ (anexo 7), de igual manera cuando analizamos mayor o igual a $53 \mathrm{~cm}$ de talla 
neonatal la muestra es escasa por lo cual el intervalo de confianza es amplio, sin embargo deducimos que el OR es mayor, observamos que si existe una asociación con la talla, vale decir a menor Índice de Pulsatilidad promedio de las arterias uterinas mayor talla neonatal, este fenómeno se observa tanto entre las 11 a 14 semanas como entre las 20 a 26 semanas como apreciamos en el anexo 7, así por ejemplo para una talla de $52 \mathrm{cms}$, el valor del IP adecuado cuando es tomado entre las 11 a 14 semanas es menor o igual 11.5 , dando una probabilidad de que ocurra el evento de 2.8 con una precisión que fluctúa entre 1.1 a 7.1 , lo mismo ocurre para las 20 a 26 semanas el punto de corte adecuado es de menor o igual a 0.77 , dando una probabilidad de que ocurra el evento de 2.1 y una precisión que fluctúa entre 1.1 a 4.0 , en cuento el sexo de neonato se aprecia que no está correlacionado con el doppler, vale decir no existen diferencias significativas en cuanto al sexo en bebes macrosómico, dicho de otra manera, el doppler de las uterinas predice igual la macrosomía así sea él bebe hombre o mujer (anexo 7).

\section{CONCLUSIONES}

Hubo un aumento del porcentaje de los recién nacidos macrosómicos sobre la población general pasando de un $6 \%$ a un $9 \%$ en 20 años (1995-2015).

Cuando asociamos la toma del doppler de las uterinas entre las 11 a 14 semanas y entre las 20 a 26 semanas apreciamos una correlación positiva con el método de Pearson siendo significativo en ambos grupos por lo cual podemos afirmar que a menor edad gestacional de toma del Índice de Pulsatilidad promedio de las arterias uterinas es más fuerte la probabilidad de que pueda predecir mayor peso fetal.

Para las 11 a 14 semanas con un punto de corte menor o igual a 1.32 del IP promedio de las uterinas, se encontró una probabilidad de 1.6 veces de que el recién nacido sea macrosómico, con una significación estadística de 0.056 para la prueba de Chi cuadrado, al realizar la curva ROC esta nos muestra una sensibilidad del $40 \%$ y una tasa de falsos positivos del $20 \%$.

Para las 20 a 26 semanas con un punto de corte menor o igual a $0.80 \mathrm{del}$ IP promedio de las uterinas, se encontró una probabilidad de 1.7 veces de que el recién nacido sea macrosómico con una significación estadística de 0.036 para la prueba de Chi-cuadrado, al realizar la curva ROC esta nos muestra una sensibilidad del $26 \%$ y una tasa de falsos positivos del $20 \%$.

Al mostrar la curva ROC en gráfico tanto entre las 11 a 14 semanas en color azul y entre las 20 a 26 semanas en color rojo, podemos afirmar que si existe una correlación en ambos con macrosomía neonatal pero su sensibilidad es baja y su tasa de falsos positivos es alta, siendo mejor la toma de la ecografía entre las 11 a 14 semanas.

\section{RECOMEDACIONES}

No se ha realizado una verdadera separación entre los macrosómicos patológicos como los bebes de madres diabéticas con respecto a los macrosómicos genéticos, es decir de padres normalmente grandes, en un futuro estudio esta variable debe de ser controlada.

El porcentaje de macrosómicos con respecto a la población total calculado por su edad gestacional al nacer representan en promedio un $14.9 \%$, mientras que el porcentaje de macrosómicos calculados por el peso mayor o igual a $4 \mathrm{~kg}$ es del $9 \%$, existiendo una diferencia marcada, esta variación del porcentaje de macrosómicos se debe al método que se use para definir macrosómico. En concordancia con la primera recomendación, lo ideal es calcular el peso fetal por percentiles de acuerdo a su edad gestacional al nacimiento, para lo cual se deberían elaborar tablas propias, ya que depender de tablas con más de cinco años no es lo adecuado ya que el perfil epidemiológico de los recién nacidos cambia conforme pasan los años.

Controlar variables confusoras que no han sido tomadas en cuenta y que influyen en el peso fetal como la diabetes gestacional, el hipotiroidismo, la obesidad, la ganancia excesiva materna en el último trimestre del embarazo, la talla materna, entre otros; esto permitirá mejorar la sensibilidad y bajar la tasa de falsos positivos, en el estudio la sensibilidad es baja y los falsos positivos son altos, lo cual indica que no es apta para diagnostico aun, hay que mejorar la metodología; esto nos permitirá confirmar si verdaderamente tomar la ecografía entre las 11 a 14 semanas es mejor que a las 20 a 26 semanas como nos muestra aparentemente el presente trabajo.

La ecografía Doppler entre las 11 a 14 semanas debería de hacerse por vía transvaginal por ser más sencilla aprovechando la toma de la ecografía genética, en el estudio se han mezclado dos técnicas una por vía abdominal y la otra por vía transvaginal, no se sabe si hay diferencias entre las técnicas en cuanto a los resultados, lo cual pudiera haber ocasionado sesgos profundos.

Las pacientes detectadas con riesgo de que sus bebes padezcan macrosomía deben de pasar por un programa de nutrición que contribuya a controlar esta patología.

Sería interesante realizar un estudio comparando la ganancia de peso materno durante la segunda mitad del embarazo ${ }^{9}$ con el presente estudio para ver quien tiene mayor fuerza de asociación para predecir macrosomía neonatal.

Finalmente, dentro del estudio Doppler de las uterinas se debe de incorporar de rutina la predicción de macrosomía, tan igual que lo usado actualmente para predecir la pre eclampsia y el RCIU, ya hemos demostrado con creces que detectar la macrosomía es tan importante como el $\mathrm{RCIU}$, para evitar en ambos grupos complicaciones en el 
paciente como son por ejemplo las enfermedades crónicas no transmisibles (ECNT), expresadas en la justificación de este estudio.

La presente investigación pretende en el futuro contribuir a reforzar los programas de nutrición, además de servir como referencia para el diseño de políticas públicas y para subrayar la importancia poderosa herramienta para predecir el riesgo de Macrosomía fetal se pueden implementar programas para controlar el peso materno en el INMP.

\section{REFERENCIA BIBLIOGRÁFICA}

1. Savona-Ventura C, Gatt M. "Short-term obstetric outcomes in obese Maltese women." International Journal of Diabetes and Metabolism 2006; 14:88-91. http://applications.emro. who.int/imemrf/Int_J_Diabetes_Metab/Int_J_Diabetes_ Metab_2006_14_2_88_91.pdf

2. Baeten JM, Bukusi EA, Lambe M. Pregnancy complications and outcomes among overweight and obese nulliparous women. Am J Public Health 2001; 91:436-40. http://www.ncbi. nlm.nih.gov/pmc/articles/PMC1446581/pdf/11236410.pdf

3. Callaway L, Prins J, Chang A, Mclintyre $\mathrm{H}$. The prevalence and impact of overweight and obesity in an Australian population. MJA 2006; 184: 56-9. http://www.ncbi.nlm.nih. gov/pubmed/16411868

4. Jensen DM, Ovesen $P$, Beck-Nielsen $H$. Gestational weight gain and pregnancy outcomes in 481 obese glucose-tolerant women. Diabetes Care 2005; 28:2118-22. https://drive. google.com/open?id=0B9vvSGijHGjoV0tZZFVtYS1OdTA

5. Sebire NJ, Jolly M, Harris JP, Wadsworth J, Joffe M, Beard RW, et al. Maternal obesity and pregnancy outcome: a study of 287213 pregnancies in London. Int J Obesity 2001; 25: 1175-82. Maternal obesity and pregnancy outcome: a study of 287,213 pregnancies in London.

6. J Albornoz, H Salinas. Morbilidad fetal asociada al parto en macrosómicos; análisis de 3981 nacimientos. Rev Chil Obst Ginecol 2005; 70(4):218-224. http://www.scielo.cl/ scielo.php?pid=S0717-75262005000400003\&script=sci_ arttext\&tlng=e

7. Ñañez L. Características del parto en la macrosomía fetal en el Instituto Especializado Materno Perinatal, Lima-Perú 2004; Tesis UNMS. http://cybertesis.unmsm.edu.pe/bitstream/ cybertesis/1863/1/\%C3\%91a\%C3\%B1ez_al.pdf

8. Ticona M., Huanco A. Macrosomía fetal en el Perú. Prevalencia, factores de riesgo y resultados perinatales. Ciencia y Desarrollo 2005. http://www.unjbg.edu.pe/coin2/ pdf/01011001306.pdf

9. Limay A. La Ganancia de peso materno en el tercer trimestre influye más en la macrosomía neonatal independientemente del peso materno pre gestacional. Revista peruana de investigación materno perinatal 2016; volumen 5, página 3. https://drive.google.com/ open?id=0B9vvSGijHGjod0VaYIIFcVUtczg

10. Limay A, Valladares $E$, Camarena $H$, et al. Índice de pulsatilidad promedio del doppler de las arterias uterinas como predictor de macrosomía fetal. Revista peruana de investigación materno perinatal 2013; volumen 2, página 8 . https://drive. google.com/open?id=0B9vvSGijHGjoWVIxV29TUENWM1k

11. Campbell $S$, Black R, Lees $C$, Armstrong V, Peacock J. Doppler ultrasound of the maternal uterine arteries: disappearance of abnormal waveforms and relation to birthweight and pregnancy outcome. Acta Obstet Gynecol Scand 2000; 79 (8): 631-4. http://www.ncbi.nlm.nih.gov/pubmed/10949225
12. Di Liberto G. Predicción de macrosomía fetal por medición ultrasonográfica de la circunferencia abdominal y resultados perinatales según vía de pato en el Hospital Ramón Rezola. Rev. Fac. Med. Hum 2011; 1(24): 24-30. http://cybertesis.urp. edu.pe/handle/urp/248

13. Stein Z, Susser M. Mental retardation in a national population of young men in the netherlands II. Prevalence of severe mental retardation. Am. J. Epidemiol. 1976; 104 (2): 159-169. https://drive.google.com/ open?id=0B9vvSGijHGjoQXVzNS1wNGg1Z2s

14. Cuentas M, Larrabure $G$. Estado nutricional de la gestante según los índices de Quetelet, Quetelet modificado y nomograma de Rosso. Ciencia e Investigación Médica Estudiantil Latinoamericana 2002, número 7. http://www. redalyc.org/pdf/717/71700707.pdf

15. Bozkurt N, Başgül Yigiter A, Gokaslan H, Kavak ZN. Correlations of fetal-maternal outcomes and first trimester 3-D placental volume/3-D power Doppler calculations. Clin Exp Obstet Gynecol 2010; 37(1):26-8. http://www.ncbi.nIm. nih.gov/pubmed/20420276

16. National Center for Health Statistics (US). Division of Vital Statistics, et al.Vital statistics of the United States. United States Bureau of the Census, 1979. https://drive.google.com/ open?id=0B9vvSGijHGjob3NzX1BfMm00eWs.

17. Informe Estadístico Anual de la Oficina de Estadística e Informática del IEMP. Año 2015. https://drive.google.com/ open?id=0B9vvSGijHGjoNGJNS29RVWFGdGM.

18. Stein Z, Susser M. A study of obstetric results in an underdeveloped community. An International Journal Obstetrics and Gynaecology 1958; volume 65 Octubre, 763-768. https://drive. google.com/open?id=0B9vvSGijHGjoWm1NYjBxRIZ2RkE

19. OMS. Informe sobre proyecciones de la mortalidad y las causas de muerte, 2015 al 2030. Septiembre 2016. https:// malariaworld.org/blog/medigo-infographic-mortality-andcauses-death-2015-and-2030

20. Stein Z, Susser M. Mental retardation in a national population of young men in the netherlands I. Prevalence of severe mental retardation. Am. J. Epidemiol. 1976; 103 (5): 477-485. https://drive.google.com/ open?id=0B9vvSGijHGjoQXVzNS1wNGg1Z2s

21. Sandoval R, Espinoza R. Antropometría materna y peso promedio de nacimiento 2001. Rev Chil Obstet Ginecol, 66(2), 99-103. http://www.ciges.cl/rdlagos/textos/pdfs/ sochog3_antrop_mat_peso_rn.pdf

22. OMS. Obesidad y sobrepeso. Nota descriptiva $N^{\circ} 311.2015$ enero http://www.who.int/mediacentre/factsheets/fs311/es/

23. Barker D, Gluckman $P$, Godfrey $K$, et al. Fetal nutrition and cardiovascular disease in adult life. Lancet 1993; Apr 10;341(8850):938-41. Review. https://drive.google.com/ open?id=0B9vvSGijHGjob0xIZWxXTONCUEE

24. Koupilová I, Leon D, Lithell H, Berglund L. Size at birth and hypertension in longitudinally followed 50-70-year-old men. Blood Press 1997; Jul;6(4):223-8. https://drive.google.com/ open?id=0B9vvSGijHGjodGVjWDVhT0N5ejQ

25. Stein $C$, et al. Fetal growth and coronary heart disease in South India. The Lancet 1996; vol. 348, no 9037 p. 1269-1273 http://citeseerx.ist.psu.edu/viewdoc/ download?doi=10.1.1.472.3049\&rep=rep1\&type=pdf

26. Samuelsson $A$, Matthews $P$, Argenton $M$, et al. Diet-induced obesity in female mice leads to offspring hyperphagia, adiposity, hypertension, and insulin resistance: a novel murine model of developmental programming. Hypertension 2008; Feb;51(2):383-92. http://hyper.ahajournals.org/ content/51/2/383.long

27. Rogers I. The influence of birthweight and intrauterine environment on adiposity and fat distribution in later life. 
International journal of obesity and related metabolic disorders: International journal of Obesity 2003; 27, 755-777. http://www.nature.com/ijo/journal/v27/n7/full/0802316a.html

28. Gluckman $P$, Hanson M. Living with the past: evolution, development, and patterns of disease. Science 2004; Sep 17;305(5691):1733-6. http://www.missmerli.com/MissMerli. com/Parents_files/Gluckman $\% 26$ Hanson_PrenatEfx $\% 20$ copy.pdf

29. Catalano $P$, Ehrenberg $H$. The short- and long-term implications of maternal obesity on the mother and her offspring. BJOG. 2006 Oct;113(10):1126-33. Epub 2006; Jul 7. Review. http://onlinelibrary.wiley.com/doi/10.1111/j.14710528.2006.00989.x/full

30. Oken E, Gillman M. Fetal origins of obesity. Obesity a Research Journal 2003;11:496-506. http://onlinelibrary.wiley. com/doi/10.1038/oby.2003.69/full

31. Curhan G, Cherton G, Willet W, Spiegelman D, Colditz GA, Manson JE, et al. Birth weight and adult hypertension and obesity in women. Circulation 1996; 94:1310-15. http://circ. ahajournals.org/content/94/6/1310.full

32. Curhan G, Willett W, Rimm E, et al. Birth weight and adult hypertension, diabetes mellitus and obesity in U.S. men. Circulation 1996; 94:3246-50. http://circ.ahajournals.org/ content/94/12/3246.full

33. Martorell R, Stein A, Schroeder D. Early nutrition and adiposity. J Nutr 2001;131:8745-805. http://jn.nutrition.org/ content/131/3/874S.long

34. FitzGerald D, Drumm J. Non-invasive measurement of human fetal circulation using ultrasound: a new method. $\mathrm{Br}$ Med J 1977 Dec 3;2(6100):1450-1. https://drive.google.com/ open?id=0B9vvSGijHGjoWk9vTEVXZDFjQ2c

35. Campbell S, Griffin D, Pearce J, et al. New doppler technique for assessing uteroplacental blood flow. The Lancet 1983; Volume 321, Issue 8326, 26 March, Pages 675-677. https://drive. google.com/open?id=0B9vvSGijHGjoOGZ6VzZsZIVWSDA

36. Zimmermann $P$, Eirio V, Koskinen J, et al. Doppler assessment of the uterine and uteroplacental circulation in the second trimester in pregnancies at high risk for preeclampsia and/ or intrauterine growth retardation: comparison and correlation between different Doppler parameters. Ultrasound Obstet Gynecol 1997; 9:330-8. http://onlinelibrary.wiley.com/ doi/10.1046/j.1469-0705.1997.09050330.x/pdf

37. Espinoza J, Kim Y, Romero R, et al. Identification of patients at risk for early onset and/or severe preeclampsia with the use of uterine artery Doppler velocimetry and placental growth factor. Am J Obstet Gynecol 2007; 196(4):326. https://www.ncbi.nlm.nih.gov/pmc/articles/PMC2190731/

38. Papageorghiou A, Avgidou K, Nicolaides K. Multicenter screening for preeclampsia and fetal growth restriction by transvaginal uterine artery Doppler at 23 weeks of gestation. Ultrasound Obstet Gynecol 2001; 18:441-9.

http://onlinelibrary.wiley.com/doi/10.1046/j.09607692.2001.00572.x/full

39. Krampl E, Espinoza J, Moscoso G, Campbell S. Maternal uterine artery Doppler studies at high altitude and sea level. Ultrasound Obstet Gynecol 2001; 18: 578-582. https://drive. google.com/open?id=0B9vvSGijHGjoNF9MZkhwSzBzZUU

40. Martínez de Villarreal L. Programación fetal de enfermedades expresadas en la etapa adulta. Med Univer 2008; 10:108-13. http://www.medigraphic.com/pdfs/meduni/mu-2008/mu082i. pdf

41. Vieau D. Perinatal nutritional programming of health and metabolic adult disease. World $\mathrm{J}$ Diabetes 2011; 2:116-33. https://drive.google.com/ open?id=0B9vvSGijHGjoRU1pc0Q0MFZuckE
42. Hall $\mathrm{J}$. The importance of the fetal origin of adult disease for geneticists. Clin Genet 2007;72:67-72. https://drive.google. com/open?id=0B9vvSGijHGjoc3|4YIJZTEVMVWs

43. Bloomfield F. Epigenetic modifications may play a role in the developmental consequences of early life events. J Neurodev Disord 2011; 3:348-55. https://drive.google.com/ open?id=0B9vvSGijHGjoenJqMGdHakh5dE0

44. Baker J, Olsen L, Sorensen T. Childhood body-mass index and the risk of coronary heart disease in adulthood. New England journal of medicine 200; vol. 357, no 23, p. 23292337. http://www.nejm.org/doi/full/10.1056/NEJMoa072515

45. Barker $D$, Osmond $C$, Winter $P$, et al. Weight in infancy and death from ischaemic heart disease. The Lancet, 1989, vol. 334, no 8663 , p. 577-580. http://wphna.org/wp-content/ uploads/2013/12/1989-09-09_Lancet_Barker._Margetts_ et_al.pdf

46. Burge $G$, et al. Epigenetic regulation of transcription: a mechanism for inducing variations in phenotype (fetal programming) by differences in nutrition during early life? British Journal of Nutrition, 2007, vol. 97, no 06, p. 1036-1046. https://www.ncbi.nlm.nih.gov/pmc/articles/PMC2211525/

47. Vo T, Hardy D. Molecular mechanisms underlying the fetal programming of adult disease. Journal of cell communication and signaling, 2012, vol. 6, no 3, p. 139-153. https://www. ncbi.nlm.nih.gov/pmc/articles/PMC2211525/

48. Ravelli G, Stein Z. Susser M. Obesity in young men after famine exposure in utero and early infancy. New England Journal of Medicine, 1976, vol. 295, no 7, p. 349-353. https://drive. google.com/open?id=0B9vvSGijHGjoVnRUNIVkd2tRdFE

49. Vickers $M$, et al. Fetal origins of hyperphagia, obesity, and hypertension and postnatal amplification by hypercaloric nutrition. American journal of physiology. Endocrinology and metabolism, 2000, vol. 279, no 1, p. E83-E87. https://drive. google.com/open?id=0B9vvSGijHGjoLVBvUVhRSHdzdXM

50. Ozaki T, et al. Dietary restriction in pregnant rats causes gender-related hypertension and vascular dysfunction in offspring. The Journal of physiology, 2001, vol. 530, no 1, p. 141-152. http://onlinelibrary.wiley.com/doi/10.1111/j.1469$7793.2001 .0141 \mathrm{~m} \times$ /full

51. Ikenasio- Thorpe $B$, et al. Prenatal influences on susceptibility to diet-induced obesity are mediated by altered neuroendocrine gene expression. Journal of Endocrinology, 2007, vol. 193, no 1, p. 31-37. http://joe.endocrinologyjournals.org/content/193/1/31.full

52. Sedova L., Seda O., Kazdova L et al. Sucrose feeding during pregnancy and lactation elicits distinct metabolic response in offspring of an inbred genetic model of metabolic syndrome. American journal of physiology. Endocrinology and metabolism,2007, 292, E1318-1324. https://drive.google. com/open?id=0B9vvSGijHGjoWW9VUVEtbFkxNXc

53. Rawana S, Clark K, Zhong $S$, et al. Low dose fructose ingestion during gestation and lactation affects carbohydrate metabolism in rat dams and their offspring. The Journal of nutrition, 1993,123, 2158-2165. https://drive.google.com/ open?id=0B9vvSGijHGjoWDBpSHE2OE1QMXM

54. Chechi $\mathrm{K}$, Cheema $\mathrm{S}$. Maternal diet rich in saturated fats has deleterious effects on plasma lipids of mice. Journal of clinical \& experimental cardiology, 2006, vol. 11, no 2,p. 129. https://drive. google.com/open?id=0B9vvSGijHGjoTjM3Z104b3ZhQms

55. Bruce K, et al. Maternal high $\square$ fat feeding primes steatohepatitis in adult mice offspring, involving mitochondrial dysfunction and altered lipogenesis gene expression. Hepatology, 2009, vol. 50, no 6 , p. 1796-1808. http://onlinelibrary.wiley.com/ doi/10.1002/hep.23205/full

56. Mccurdy $\mathrm{C}$, et al. Maternal high-fat diet triggers lipotoxicity in the fetal livers of nonhuman primates. The Journal of clinical 
investigation, 2009, vol. 119, no 2, p. 323-335. http://www.jci. org/articles/view/32661

57. Thangaratinam $S$, Jolly K. Obesity in pregnancy: a review of reviews on the effectiveness of interventions. British journal of obstetrics and gynaecology, 2010, vol. 117, no 11, p. 1309-1312. http://onlinelibrary.wiley.com/doi/10.1111/j.14710528.2010.02670.x/full

58. Catalano $P$, et al. Fetuses of obese mothers develop insulin resistance in utero. Diabetes care, 2009, vol. 32, no 6, p. 10761080. http://care.diabetesjournals.org/content/32/6/1076

59. Gademan M, van Eijsden M, Roseboom T, et al. Maternal prepregnancy body mass index and their children's blood pressure and resting cardiac autonomic balance at age 5 to 6 years. Hypertension, 2013,62, 641-647.

60. King $\bigvee$, et al. Maternal obesity has little effect on the immediate offspring but impacts on the next generation. Endocrinology, 2013, vol. 154, no 7, p. 2514-2524. http://press.endocrine. org/doi/full/10.1210/en.2013-1013

61. Gilmartin A, Ural S, Repke J. Gestational diabetes mellitus. Reviews in obstetrics \& gynecology, 2007, vol. 1, no 3, p. 129-134. https://www.ncbi.nlm.nih.gov/pmc/articles/ PMC2582643/

62. Peuchant $\mathrm{E}$, etal. Oxidative and antioxidative status in pregnant women with either gestational or type 1 diabetes. Clinical biochemistry, 2004, vol. 37, no 4, p. 293-298. https://drive. google.com/open?id=0B9vvSGijHGjoMmIDV2pzQzNJazQ

63. Green J, et al. Glucose tolerance in pregnancy: ethnic variation and influence of body habitus. American journal of obstetrics and gynecology, 1990, vol. 163, no 1, p. 86-92. https://drive. google.com/open?id=0B9vvSGijHGjoZ29Xck1od3k0c3M

64. Mardones $S$, et al. Desarrollo de una curva patrón de incrementos ponderales para la embarazada. Rev. Med. Chile, 1997, vol. 125, no 12, p. 1437-48. https://drive.google. com/open?id=0B9vvSGijHGjoTWFicmpPZEdudkk

65. Atalah E, et al. Propuesta de un nuevo estándar de evaluación nutricional en embarazadas. Rev. Med. Chile, 1997, vol. 125, no 12, p. 1429-36. https://drive.google.com/ open?id=0B9vvSGijHGjoQW9ReGVSelAwc0k

66. Mardones F. Evolución de la antropometría materna y del peso de nacimiento en Chile, 1987-2000. Revista chilena de nutrición, 2003, vol. 30, no 2, p. 122-131. http://www.scielo.cl/scielo. php?pid=S0717-75182003000200006\&script=sci_arttext

67. IOM Pregnancy Weight Guidelines. Weight gain during pregnancy 2009. Institute of medicine and national research council of the national academies. Washington, D.C. http:// www.nap.edu/read/12584/chapter/1

68. Surkan $P$, Hsieh $C$, Johanson $A L$, et al. Reasons for increasing trends in large for gestational age births. Obstet Gynecol 2004; 104: 720-6. https://drive.google.com/ open?id=0B9vvSGijHGjoOXdtRHNDYOF3WnM

69. Weiss J, Malone F, EmigD, etal. Obesity, obstetric complications and cesarean delivery rate-A population-based screening study. Am J Obstet Ginecol2004; 190:1091-7. https://drive. google.com/open?id=0B9vvSGijHGjoNzdyY2FYZVRLclE

70. Kac G, Velasquez-Melendez G. Gestational weight gain and macrosomía in a cohort of mothers and their children. J Pediatr (Rio J). 2005 Jan-Feb;81(1):47-53. https://drive. google.com/open?id=0B9vvSGijHGjoMVJNVW1QUzhHQIU

71. Rhodes J, Schoendorf K, Parker J. Contribution of excess weight gain during pregnancy and macrosomía to the cesarean delivery rate, 1990-2000. Pediatrics 2003;111:1181$5 . \quad$ http://pediatrics.aappublications.org/content/111/ Supplement_1/1181.short

72. Bertoldi L, Bartholow B, Serrate S, Branchtein L, Schmidt M, Fleck T. Assessment of weight gain during pregnancy in general prenatal care services in Brazil. Cad Saúde Pública, Río de Janeiro 2001; 17(6): 1367-74. http://www.scielosp.org/ pdf/csp/v17n6/6962.pdf

73. Lagiou $P$, Tamimi $R$, Mucci $L$, et al. Diet during pregnancy in relation to maternal weight gain and birth size. Eur J Clin Nutr 2004; Feb;58(2):231-7. http://www.nature.com/ejcn/journal/ v58/n2/full/1601771a.html

74. Caughey A. Obesity, weight loss, and pregnancy outcomes. The Lancet 2006; 368 (9542). http://www.ncbi.nlm.nih.gov/ pubmed/17011927

75. Villamor E, Cnattingius S. Interpregnancy weight change and risk of adverse pregnancy outcomes: a population-based study. The Lancet 2006; 368 (9542) 1164-7. https://drive. google.com/open?id=0B9vvSGijHGjoaXY5TUdsMklaN2s

76. Winkvist $A$, Stenlund $H$, Hakimi $M$, et al. Weight-gain patterns from pregnancy until delivery among women in Central Java, Indonesia. Am J Clin Nutr 2002; 75:1072-7. https://drive. google.com/open?id=0B9vvSGijHGjoeUtSM002WkRMOEk

77. Abrams B, Altman S, Pickett K. Pregnancy weight gain: still controversial. Am J Clin Nutr 2000; 71 (suppl):1233S-41S. https://drive.google.com/ open?id=0B9vvSGijHGjoTjQtX3FDMExZVEE

78. Grados F, Cabrera R, Diaz J. Estado nutricional pregestacional y ganancia de peso materno durante la gestación y su relación con el peso del recién nacido. Rev Med Hered 2003; 14: 128-33. https://drive.google.com/ open?id=0B9vvSGijHGjoUGRpWUNxSEVxc3M

79. Leary S, Fall C, Osmond C. Geographical variation in relationships between parental body size and offspring phenotype at birth. Acta Obstet Gynecol Scand. 2006;85(9):1066-79. https://drive.google.com/ open?id=0B9vvSGijHGjoRDJHTkM5VndvbTA

80. Ounsted M. Ounsted C. On fetal growth rate: Its variations and their consequences. In: Clinics in Development Medicine (46). Spastics International Medical Publications. Philadelphia, PA: Lippincott, 1974

81. Cutié $M$, Figueroa $M$, Segura $A$, et al. Macrosomía fetal Su comportamiento en el último quinquenio. Rev Cubana Obstet Ginecol 2002; 28(1): 34-41 https://drive.google.com/ open?id=0B9vvSGijHGjoMEZ3QnVMeUIRYU0

82. Stotland N, Hopkins L, Caughey A. Gestational weight gain, macrosomía and risk of cesarean birth in nondiabetic nulliparas. Obstet Gynecol 2004; 104: 671-7. https://drive. google.com/open?id=0B9vvSGijHGjoSng5ajhKRHgwQWs

83. Loaiza S, Atalah E. Factores de riesgo de obesidad en escolares de primer año básico de Punta Arenas. Revista chilena de pediatría 2006; volumen77 número 1 https://drive. google.com/open?id=0B9vvSGijHGjoRWJFeEd1ZXBSWVU

84. Gomez O, Figueras F, Gratacós E. Reference ranges for uterine artery mean pulsatility index at $11-41$ weeks of gestation. Ultrasound Obstet Gynecol 2008; Volume 32, Issue 2, 128-132. http://onlinelibrary.wiley.com/doi/10.1002/ uog.5315/full

85. Aplin J. Hypoxia and human placental development. J Clin Invest. 2000;105:559-60. http://www.jci.org/articles/ view/9512/version/1/pdf/render

86. Hempstock J, Jauniaux E, Greenwold N, et al. The contribution of placental oxidative stress to early pregnancy failure. Hum Pathol. 2003; 34: 1265-75. https://drive.google. com/open?id=0B9vvSGijHGjoTk0tVHI2Z2xnQm8

87. Ticona $M$, Huanco $A$. Curvas de crecimiento intrauterino propias del Perú y su efecto en la identificación de una nueva población neonatal de alto riesgo nutricional. Rev Perú Med Exp Salud Pública 24(2) 2007. http://www.bvs.ins.gob.pe/ insprint/cindoc\%20/informes_tecnicos/73.pdf

\section{ORCID iDs}

